Special Issue on KEER 2012

ORIGINAL ARTICLE

\title{
Towards a Kansei-based User Modeling Methodology for Eco-design
}

\author{
Francis RASAMOELINA, Carole BOUCHARD and Améziane AOUSSAT \\ Product Design and Innovation Laboratory, Arts et Métiers ParisTech, 151 Boulevard de l'Hôpital, 75013 Paris, France
}

\begin{abstract}
We propose here to highlight the benefits of building a framework linking Kansei Design (KD), User Centered Design (UCD) and Eco-design as the correlation between these fields is barely explored at the current time. Therefore we believe Kansei Design could serve the goal of achieving more sustainable products by setting up an accurate understanding of the user in terms of ecological awareness, and consequently enhancing performance in the Eco-design process. At the same time, we will consider the means-end chain approach inspired from Marketing research as it is useful for identifying ecological values, mapping associated functions and defining suitable design solutions. Information gathered will serve as entry data for conducting scenario-based design and supporting the development of an Eco-friendly User Centered Design methodology (EcoUCD).
\end{abstract}

Keywords: Kansei Design, Experience Design, User Modeling, User Centered Design, Eco-design

\section{INTRODUCTION}

This article aims to achieve two objectives: firstly it reviews the literature in order to find approaches from various topics that are relevant to link the fields of Eco-design, User Centered Design and Kansei Design. Next, it compiles these ideas and proposes a theoretical model that describes this particular association. Thus we will provide here a brief overview of the notable breakthroughs in these areas and review the most relevant technologies developed in terms of user involvement. We will focus especially on trends in modeling that allow integration with the field of Eco-design. This article is subsequently divided into six parts. Part 1 presents an overview of the analysis of the state of the art results. Part 2 introduces the pathway with a general assertion on sustainability and its connection with Eco-design and Green Kansei, and we will discuss what is known as Eco-design. Part 3 evaluates the capabilities of Eco-design approaches to integrate users. Part 4 focuses on the user and makes a general statement on the current principles for integrating and evaluating users in User Centered Design studies. Part 5 goes further toward an advanced definition of users by asserting Kansei-based factors that we call Eco-Kansei, then describing what is known as Green Kansei for Eco-design. And finally, we will conclude in part 6 by suggesting a new theoretical model as an initial framework of attempting to merge Kansei Design, User Centered Design and Eco-design processes.

\section{GENERAL OVERVIEW}

To begin with, we will start by giving an overview of the state of the art results. The basic context of our work is clearly considered as cross disciplinary and requires a wide and macro vision of the subject. The following state of the art tries to focus on a set of specific themes identified in some relevant studies, which are linked to the main fields discussed above. These are:

- Studies that propose an integration of users in the design process, such as "User Centered Design" studies (UCD);

- Studies that provide a characterization of emotions and subjectivity onto the definition of product, such as "Kansei / Affective Design" (KD);

- Studies that provide an environmental consideration in the design process, or "Eco-design".

As a consequence, the intersection of these three areas allows us to define some relevance levels ranging from 1 to $\mathrm{n}$ where 1 is the closest to the objective. The first level is reached once a study which combines the three fields is identified; the level 2 if an association between only two fields is found, and so on. It would go up to level 3 if we focus only on key areas and go above if we start looking into the more or less divergent areas other than the initial themes. These latest studies may be of minor interest but would likely contain useful information. Figure 1 shows a brief quantitative summary of the relative findings. The results let us state that no significant amount of data were 


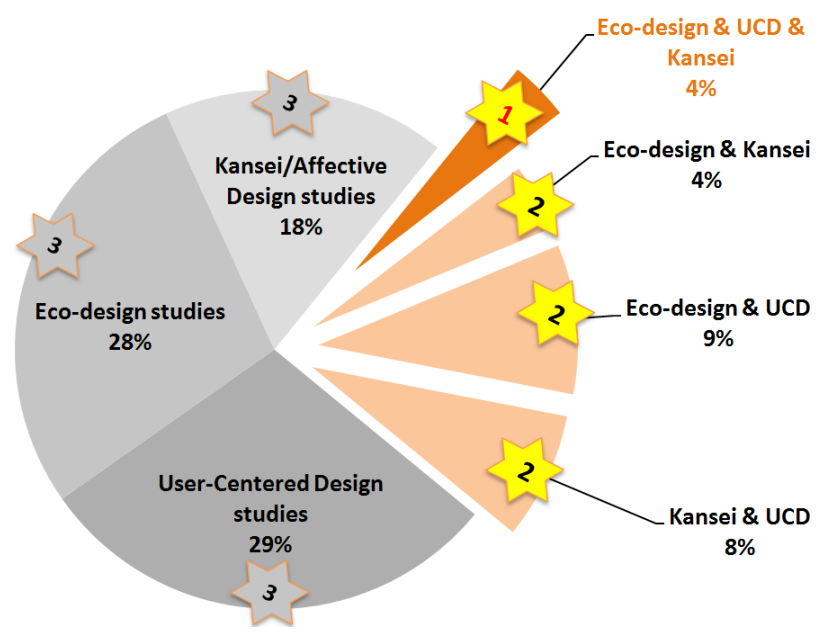

Figure 1: Key fields distribution among 147 references.

found regarding the crossed relevance. That assumption shows a scientific gap, and allows to say that this actual investigation is a valuable study that could serve as an innovative support for the research field.

\section{FROM SUSTAINABILITY TO ECO-DESIGN}

This second part introduces the general concepts of Eco-design and Green Kansei. We will show the place of these key areas into a wider scale by emphasizing their interaction with global sustainability development. Sustainability has gathered more and more interest over the past decades, regarding both industry and research. Sustainability is a global principle which covers multiple dimensions such as social, economical and environmental interests [94]. That later one turns out to be more related than others, thus more often associated with sustainability principles. By stating on a brief history, politics were the first concerned with the environmental impact, then followed by administration collectivities and some proenvironmental organizations, then later expanded at a wider scale. Nowadays embracing eco-friendly principles almost become a fashion practice among concerned stakeholders in many fields, as green concept turns out to be an interesting issue. Today, that global trend brought by ecological interests is taken into account into product design development, through the principle of the so wellknown Eco-design, or Design for Environment.

\subsection{Sustainable Green Kansei}

Product Design and Eco-design are closely related to the sustainability development. This relationship is mainly inclusive as presented in the model of Tischner and Charter [82] where they clearly describe the link between
Product Design, Eco-design, Sustainable Design, and Sustainable Development. Elias [21] then explains how Product Design is linked to the global sustainability process.

Today, further inclusions should be considered aiming towards an ecological implication for Kansei. In fact, Kansei Design must be regarded as the integration of the subjective evaluation of Kansei factors into sustainable design. Mapping the Kansei Design would lead to the enrichment of Tischner and Charter's model [21,82]. As shown in Figure 2, this inclusion allows us to introduce the ecological part of Kansei through the notion of "Green Kansei".

For the record, Eco-design is defined by the International Standard Organization - ISO/TR 14062 - as the integration of environmental aspects into product design and development [1]. Another definition of Eco-design comes from the European Union. Two directives related to Eco-design have been adopted by the European Union: Directive 2005/32/EC [27] and Directive 2009/125/EC [28]. The first directive regulates energy-using products $(\mathrm{EuP})$ while the second is its replacement and regulates energy-related products (ErP). The difference between EuP and Erp is related in the Table 1 [93]. Indeed, according to Directive 2005/32/EC for Energy products [27], Eco-design means

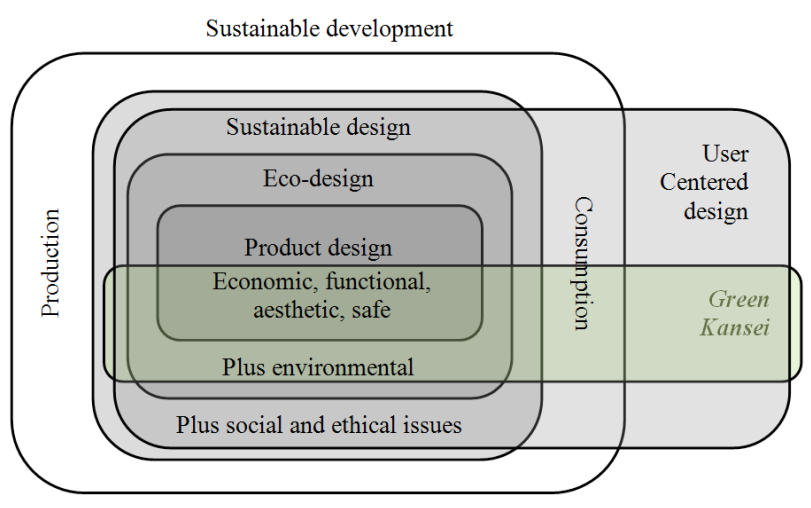

Figure 2: Eco-design and sustainable development (Adapted from Tischner et al. [82 in 21])

Table 1: Difference between EuP and Erp [93]

\begin{tabular}{|c|c|}
\hline Energy-using Products & Energy-related Products \\
\hline $\begin{array}{l}\text { require energy (electricity, } \\
\text { fossil fuels or renewable } \\
\text { energy) input to work as } \\
\text { intended; } \\
\text { - includes products that } \\
\text { generate, transfer or measure } \\
\text { energy; } \\
\text { excludes products that } \\
\text { transport people or goods. }\end{array}$ & $\begin{array}{l}\text { - impact energy consumption } \\
\text { during their use; } \\
\text { - examples include } \\
\text { construction materials such } \\
\text { as windows \& insulation and } \\
\text { water-using products such as } \\
\text { shower heads \& tap; } \\
\text { - includes EuP; } \\
\text { - excludes products that } \\
\text { transport people or goods. }\end{array}$ \\
\hline
\end{tabular}


the integration of environmental aspects into product design in order to improve environmental performance of the energy-using products (EuP) throughout its lifecycle. Eco-design aims at reducing the impact of the product life cycle on the environment, in energy consumption, carbon emission, materials, packaging and transport, chemical substances, potential toxicity, recyclability and durability throughout the whole product lifecycle.

\subsection{Eco-design tools \& methodologies}

We stated that Eco-design methodologies aim to support the creation of products that are less harmful for the environment. In that way, designing with sustainable objectives turns out to be a great challenge for manufacturers as it implies for designer to understand the whole life cycle of the product. Life Cycle Assessment (LCA) is the first tool that is commonly used for Eco-design. LCA runs from raw materials extraction, manufacturing, packaging, distribution, product use up to the final disposal. In fact, an efficient Eco-design method should take into account the environmental impact of each phase of the product lifecycle. In the same way, another efficient tool is Environmental Effect Analysis (EEA). It is used to identify the product eco-profile by retrieving the relevant factors for the reduction of the environmental impact during all lifecycle stages. The example of the Figure 3 [25] highlights the importance of performing this couple of tools for Eco-design studies. Indeed, it shows that the consumption differs from one to another lifecycle phase depending on the product characteristics.

Current Eco-design methodologies offer various guidelines that formalize the design requirements retrieved from EEA $[10,80]$. Software such as "Eco-design Pilot" $[24,91,92]$ exists helping to assess the EEA on the product lifecycle. Various Eco-design methods are also available in the literature [49, 50, 80, 81]. The use phase is also taken into consideration by some

\section{Standard Vacuum cleaner eco-profile example}
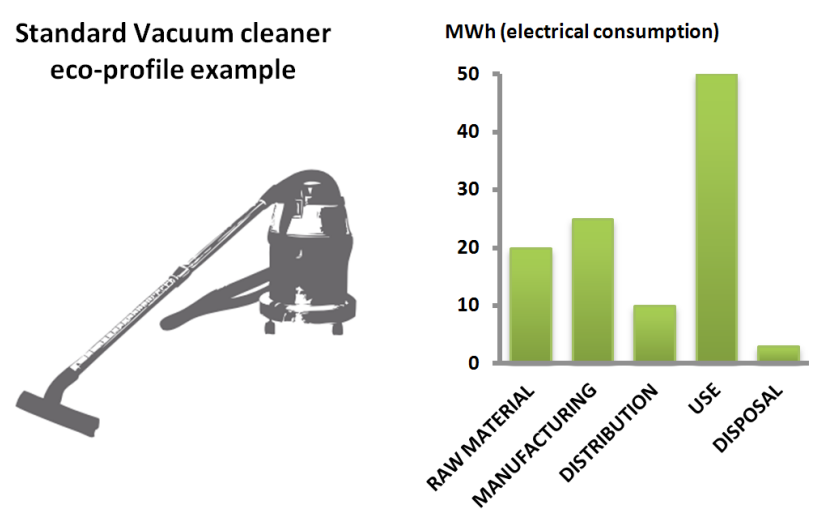

Figure 3: Example of standard vacuum cleaner eco-profile [25]. studies $[10,21,51]$. In addition, talking about the specific use phase introduces the user himself in Eco-design. That is the main interest of the next chapter.

\section{INTRODUCING THE USER IN ECO-DESIGN}

After giving an overview of Eco-design principles, we intend to see in this part the possibilities for integrating users in its main concept.

\subsection{User and use phase}

In the first place, designing for the environment brings a strong enthusiasm among scientists in several research fields, whereas various methodologies and tools were implemented and validated through predictive analysis of the whole product lifecycle. Life Cycle Assessment (LCA) runs from the extraction of raw materials to disposal of the product, passing through manufacturing, distribution and use phases, and helps us understand the environmental impact of a designed product. The use phase is the key specific element that drives our current work and brings the basic assumption of our statement. The use stage is an important step of the product lifecycle as it provides a sizeable part of environmental impact. It appears that environmental performance in the use phase is difficult to assess as the available indicators in terms of environmental performance are merely about product-related rates related to energy consumption or carbon dioxide rejection.

Moreover, impacts that occur during the use phase are often determined by analyzing users' behavior [7]. The behavior of the user dealing with products is interesting to evaluate, in the perspective of shifting to a more sustainable practice. Influencing the behavior of users is therefore a difficult task. However, designers have the tools to reduce the environmental impacts of the product use and induce changes in that user behavior towards more sustainable behaviors $[7,26,90,48]$.

\subsection{Mapping ecological user behavior}

A green product is defined as a product which complies with environmental issues throughout its life cycle [69]. From a general point of view, the association of the product design with environmental awareness necessarily involves a consideration of human factors [78]. Product design for sustainable environment is a "human-centered" discipline. Following this statement, Eco-design and User-centered design can therefore be considered as closely related. Thus, in the category of specific design methods, we can cite Lilley's model [46]. Her approach "Design for Sustainable Behavior" explores how design 
can be used to influence the behavior of users in order to shift towards more sustainable practices. The Figure 4 resumes her point of view. Indeed, she describes three strategies to change user behavior and evaluates their effectiveness, by using a part of design methodologies found from the literature and also by enriching them with results from the analysis of a case study.

These three strategies are the main current approaches that may be considered throughout the scientific community as frameworks for a user-centered eco-design methodology.

- Eco-feedback / Eco-retroaction [38,55];

- Behavior steering [4,39];

- Persuasive technologies [5,29].

Lilley's model was later reused, enriched and updated by other authors, for mapping the association of user behavior and environment [7]. It then appears that the user can be affected by the information presented to him and his behavior could be influenced in this case.

\section{MODELING USERS IN USER CENTERED PRACTICES}

In this part, we will focus especially on user elicitation and make a general statement on the current principles for integrating and evaluating users in generic user centered design studies. We will talk about User Experience, and the importance of designing this experience using User Centered Design methodologies. In addition, we will see why usability assessment tools are useful for conducting this evaluation.

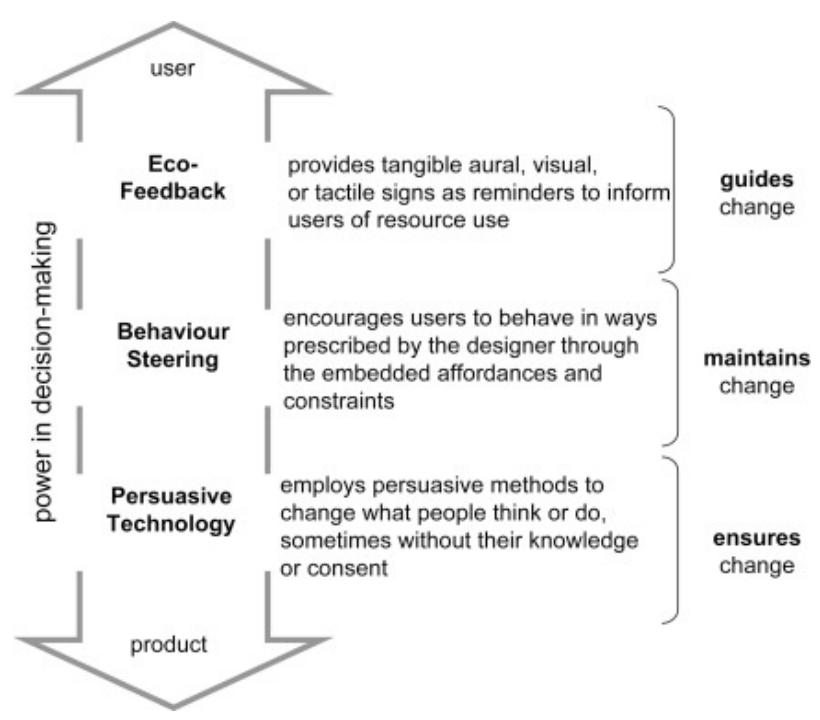

Figure 4: Lilley's strategies for designing sustainable behavior [46]
However, remaining close to environmental considerations, we can assert that the application of Eco-design strategies has significantly reduced the environmental impacts of the life cycle of the product [45]. Moreover, in order to understand the use phase, it is essential to have information about the user in order to adapt the product to his characteristics and preferences. And by "the user", we mean both the physical user, with his cognitive and psychological patterns and also the context of use. Therefore, it is necessary to consider the whole environment of the user to define the use phase. Nevertheless, such investigation requires a complete understanding of the user-product interaction process. According to the field of User Centered Design or Human Centered Design, users have been taken into account in the design process for years. Users may also be involved in the early design process through the practice of Participatory Design [62].

These user centered studies point out the user characteristics and let their needs to be expressed. The main advantage of relying on such methodologies is rather important, since these practices allow enhancing the usability performance of the product by matching the user needs with product design parameters. Thus, defining the user leads to the User Modeling techniques (UM). User Modeling is an area that has been widely considered in the research community for the past forty years. Early User Modeling techniques commonly refer to the area of Computer Science, as it is known more precisely in the Information Science and Artificial Intelligence, and basically used to improve the user implication on Hypermedia and Adaptative Systems. Latest evolutions concern extensive implications on Human-Computer Interaction, Interface Design and today it is more and more implemented in consumer product design. Various techniques are used in user modeling, such as heuristicbased formal evaluation, brainstorming, expert reviews in sociology or ergonomics, direct tests on physical or virtual prototypes, acceptability surveys, interviews, observations, participatory design, task analysis, focus group, scenarios production and application, experience through ecological-economical paper and ethnographic approaches [12].

\subsection{Designing the User Experience}

From this point of view, products are perceived as perfect if they give the most suitable user experience. In order to reach that objective, two major steps are necessary. The first step is to assess a correct elicitation of the target user through User Modeling (UM) and the 
second is to design the suitable experience through the interaction of this user with the product, also referred as Experience Design (XD). Following this statement, Experience Design (XD) and User Modeling (UM) are considered as user-centered studies, as they are to be linked with the field of User Centered Design (UCD). Moreover, despite most User Centered Design methodologies are oriented towards specific applications, an interesting model set up by a group of experts from the Usability Professionals Association otherwise attempts to achieve a typical and standard User Experience Design methodology [87]. Although the main framework of a classic UCD principle [3] is present, the process is divided into four main steps: Analysis, Design, Implementation and Deployment [87].

\subsection{User Centered Design overview}

User Centered Design (UCD) is a multidisciplinary design practice based on the active involvement of users. The UCD is considered the key to ensuring maximum usability of the product. The aim of this approach is then to improve the understanding of use and task requirements, thus ensuring the optimization of iterative phases between design and evaluation. To help justify its importance, the UCD approach is formalized by the International Standard Organization (ISO), making it a useful tool for any user-focused approach [3]. In practical terms, UCD is currently applied in industrial firms of all sizes, and stimulates technological development through the early inclusion of end users [54]. The Figure 5 below shows the main steps of the UCD activities proposed by ISO.

The integration of the user in the design process has taken a while to be mature [52,79]. Some authors demonstrate that this practice may also become an important factor of innovation [71]. The user himself is

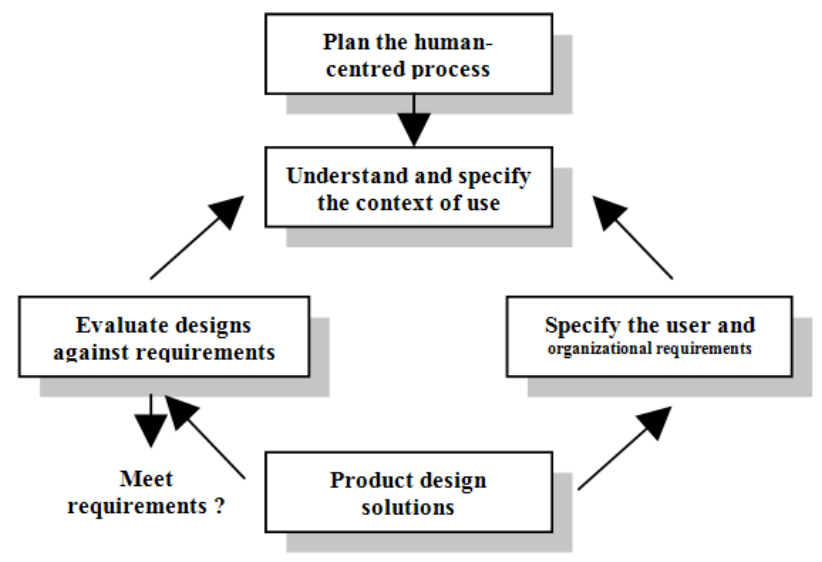

Figure 5: Key human-centered design activities, from ISO 13407. not the only entity role in User Centered Design, the context of use is an important step in the analysis that has been taken into account. Various studies demonstrate the importance of this vision [77,90]. A typical example of this assumption comes from Wever et al as shown in the Figure 6 below.

\subsection{Usability assessment as a validation tool}

Dealing with the analysis of use phase leads us to consider usability assessment methodologies. This step helps us define usability goals and validate the potential user-friendliness of any product concept. Usability tests that are conducted throughout product development to guide the design are called formative. These tests focus on identifying the strengths and weaknesses of the product and contribute to their iterative improvement. In contrast, tests that are conducted at the end of product development are called summative [23]. Usability is often defined as "the degree to which a product can be used by specified users to achieve defined objectives with effectiveness, efficiency and satisfaction in a specified context of use". Effectiveness is defined as "the accuracy and completeness with which users are able to achieve specific goals", efficiency as "the provision of resources expended in relation to the accuracy and completeness with which users will have achieved the objectives", and satisfaction as "comfort in use, and a positive attitude towards subjective interaction with the product" [2]. The usability of a product is evaluated by analyzing data collected by different methods. Dumas \& Salzman drew up a list of comparative methods in describing the basics of the different techniques, their strengths and weaknesses, measuring their characteristics, their validity and reliability, and how they are applied to the development and evaluation of products [23]. Among the ideas put forth in the literature on evaluation of usability and affordance in design $[59,86]$, it appears that ethnographic methods are

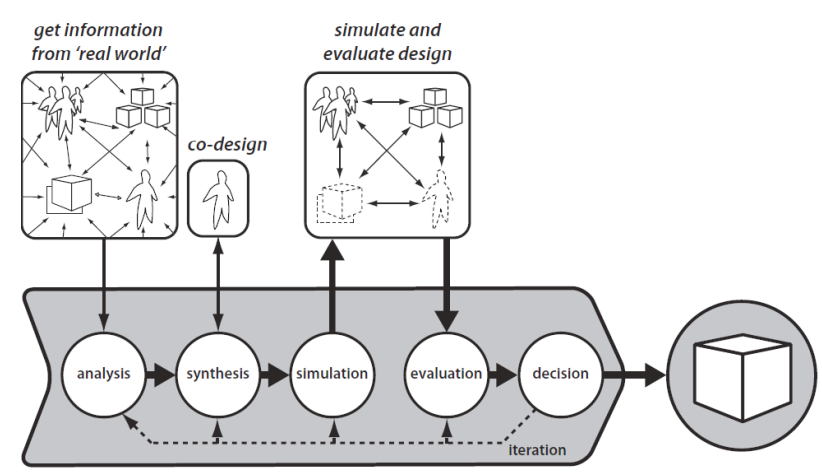

Figure 6: User Centered Design Process including context of use, by Wever et al $[73,90]$. 
particularly suitable for considering environmental impact, regarding the quality of immersion that allows collecting real data and the in situ characteristic of the observation [23].

\section{GREEN KANSEI FOR ECO-DESIGN}

This part summarizes these different visions of user and then introduces a further user definition by integrating Kansei-based factors or Eco-Kansei. The various fields that we introduced in the previous chapter will serve as a concrete support for its integration with the Kansei notions. That is the main innovative point that makes this assertion an interesting support for a multidisciplinary study.

\subsection{About Kansei \& Kansei Engineering}

The importance of pointing out the subjective perceptions associated with the emotion was put forward by several scientists [31,61]. Various techniques have emerged to take into account the integration of these features in the product design. Two major research streams about emotional approach exist with fairly similar views [11], as listed below.

- On the one hand, the concept of Kansei Engineering coming from Japan, initially developed by Mitsuo Nagamachi offers to measure the subjective values associated with the products and translate them into product attributes $[57,13,75,76,53,19]$;

- On the other hand, there is an European approach called "Emotional Design" used by authors such as Norman and Overbeeke $[65,31,60,61,74]$ that would be rather associated with Experience Design, and the creation of feelings of attachment to the product.

Thus, Kansei Engineering measures emotional needs and translates them into design elements, in order to provide end-users with greater satisfaction and product acceptance. The transcription of the subjective characteristics experienced by the user (Kansei) towards perfect design elements remains one of the main challenges of emotional design [65]. Various methods to measure subjective emotions exist from statistics-based methods [40], swarm modeling [86] to neural networksbased methods [17,22].

There are many examples of affective dimensions considered in the literature, especially related to usability considerations which are relevant for our work because they directly affect user behavior. Examples are found in electronics [47], computer interfaces [41], and food products [42]. It is also shown that errors or faux pas occur when product use leads to negative emotional responses and thus to a loss of usability [84]. Furthermore, Han [33] proposes to model emotional response with respect to product usability. His study provides a systematic approach for improving the emotional responses (objective and subjective) of consumer electronics. His approach can be used in the design and evaluation phase of the development process. It can help designers and developers identify critical design elements, diagnose usability problems, and predict the level of usability of consumer electronic products. The approach developed in this study is also applicable to other consumer products (such as appliances, automotive, communication devices, and so on), subject to minor changes. Usability is often defined along two main dimensions: a dimension in terms of performance objective and a subjective dimension related to the image or impression aroused. Subsequently, these subjective dimensions of usability can easily be linked to intangible Kansei factors, and satisfy our methodology principle.

\subsection{Eco-Kansei}

Green Kansei can be introduced as a central topic in our work. Indeed, we believe users environmental awareness is closely related to the subjective notions usually covered by Kansei.

Both concrete and abstract Kansei factors may be taken into account through Eco-design, as they help linking ecological-awareness values and/or provoked emotions to product attributes. For example, concrete (or tangible) factors which are related to product parameters such as color, forms associated, light materials or texture may be related to environmental awareness. Abstract (or intangible) factors could also be set as parameters for understanding the user (users terminal values, life experience, emotion associated with a particular content, opinions, culture $[34,35,36,70]$, moods and semantics surrounding the product $[72,64,67]$.

We can sum up these elements into the term of eco- $X$, as we talk about eco-Kansei factors regarding the Kansei factors for environment, such as eco-values, eco-moods, eco-culture, eco-emotions, and so on.

These elements are useful to assess a complete understanding of users and their relationship with environmental issues. They help designing user profiles or personae that will fit perfectly with the usability goals related to environmental issues. These elements will be useful as well for completing an UCD process. 


\subsection{Towards an Eco-User profile}

In order to profile the user, we will introduce here what is known about persona. A persona is a user profile that allows designers to highlight the objectives of the individual during the use of an artifact. This is an archetypal representation of actual or potential users of the product, which aims to highlight the behavior patterns of users, their goals and motivations with a fictional description [8,9].

Personae can focus on the user and the context of use with their fictitious characteristics $[32,37]$. The integration of personae has many advantages in product design [56], particularly on understanding the needs of the user but also the communication between designers. Several features should be considered for the identification of user profiles represented by a persona [43], in this case, these features are detailed in the Table 2 below.

The creation of the personae should be based on established real data $[30,68,63]$, which can be collected directly from users, or through more indirect sources [14]. Various market research surveys exist regarding environmental behaviors. They can be useful for pointing out the segmentation of users and creating personae [20,83].

\subsection{Scenario analysis}

Analyzing the use phase must not be seen as a static process. User behaviors evolve while performing any task. Thus we introduce scenario analysis in order to assess this dynamic evolution in the use phase. In fact, personae and scenarios are closely related. In other words, it would be interesting to focus on scenarios as they share attributes and similar principles with the personae. Scenarios are stories, these are stories about people and their activities [15]. However, the literature emphasizes that the combination of scenarios and personae would be more convincing because the scenarios are less effective when their construction is not associated with personae $[32,58]$.

Table 2: Persona characteristics, by Kujala \& Kauppinen [43].

\begin{tabular}{|c|c|}
\hline Categories & Characteristics \\
\hline $\begin{array}{l}\text { Personal } \\
\text { characteristics }\end{array}$ & $\begin{array}{l}\text { - Age, sex, education, job type, socio-economic } \\
\text { status, role in organization. } \\
\text { - Lifestyle, personality, emotions and attitudes } \\
\text { (e.g. toward using a technology). } \\
\text { - Skills. } \\
\text { - Physical abilities and constraints, e.g. poor } \\
\text { eyesight, color blindness, etc. }\end{array}$ \\
\hline $\begin{array}{l}\text { Task related } \\
\text { characteristics }\end{array}$ & $\begin{array}{l}\text { - Goals and motivation. } \\
\text { - Tasks } \\
\text { - Usage (heavy vs. light, frequency, indirect or } \\
\text { remote). } \\
\text { - Training and experience (from novice to expert). }\end{array}$ \\
\hline $\begin{array}{l}\text { Geographic } \\
\text { and social } \\
\text { characteristics }\end{array}$ & $\begin{array}{l}\text { - Location: regions, countries, continents, market } \\
\text { areas. } \\
\text { - Cultures and other circumstances. } \\
\text { - Social connections, societies, organizations. }\end{array}$ \\
\hline
\end{tabular}

\subsection{From values to product attributes}

The Means-End Chain theory (MEC) in Marketing Research can highlight the links between the identified values and product attributes through a simple means-end chain. A means-end chain is a simple knowledge structure containing interconnected meanings through which product attributes are seen as means-to-ends or personal values $[6,89]$. The product attributes, consequences and values (ACV) and, above all, the link consumers establish between them constitute the essence of the MEC [18].

\section{TOWARDS A MODEL PROPOSAL}

In this final part, we will conclude by proposing a new theoretical model as an initial framework attempting to merge the processes of Kansei Design, User Centered Design and Eco-design. This model is created according to the previous conclusions of each part discussed in the article.

In the state of the art, we noticed that few studies attempted to merge Kansei and Eco-design. The various proposed approaches found in the literature [44, 88, 17, 16] are a source of interesting ideas, but the diversity of applications does not confirm their relevance to global methods of Eco-design. The impacts identified are still focused on one single phase of the life cycle and does not take into account effects on other cycles. From a methodological point of view, an interesting point of view has been already advanced and allowed the integration of Kansei, by considering Experience Design and methods of Ecodesign, and then taking into account human values, semantics, functions and affordance [12].

In order to settle ideas about our model, we will consider these various statements in Table 3, following the literature review presented.

Table 3: Theoretical assumptions of the new model.

Standard Design model is used as a first support of the methodology: Pahl \& Beitz [66] or Ulrich \& Eppinger [85]

Eco-design principles come as a layer above standard design, and integrates tools such as LCA and EEA $[1,10,49,50,80,81]$, actual user-related Eco-design principles are also presented as another layer $[4,5,29,38,39,55]$

User-Centered Design methodology may include the four basic phases of the UPA User Experience Design process : Analysis including field works, user definition and Kansei Engineering, Design, Implementation and Deployment. [3,87]

MEC theory $[89,6,18]$ from the marketing research is a tool for translating the values to product attributes and comes across the Analysis and Design phase.

Eco-Kansei factors, user experience, usability, affordance and values perception come as an iterative group data that makes the link between the Standard Design method and UCD Methodologies. 
Following these assumptions, we can propose on Figure 7 a theoretical framework model which integrates the various point of views presented in this article.

\section{CONCLUSION}

A major assumption in our research is that Kansei studies could expand our vision of user modeling for Eco-design by introducing advanced concepts in the subjective definition of users, and by building new user models encompassing complex dimensions such as ecovalues and eco-moods. We focused here on studies that take into account the subjective perceptions of users of the products in design, with a particular interest in the notions of value and semantics towards the environment as we believe Kansei studies are actually of a great interest for Eco-design. With regard to this, we introduced the notion of Eco-Kansei to define Kansei factors which are relevant for environmental awareness. Eco-Kansei may be associated with common User Centered Design techniques on its analysis phase and clearly enriches the definition of end-user profiles or personae. Other Kansei factors are still implemented, then usability testing are conducted towards the development process to ensure that the solution fits with the users' usability profile.

Building a framework linking Kansei Design, User Centered Design and Eco-design is the main point of this paper. According to a literature review, a new user model which integrates the three key fields: Eco-design, User Centred Design and Kansei is proposed. This theoretical model is only set into a macro vision in order to let each areas be further improved into more specific procedures. Protocols and task analysis will be applied in experimental context after selecting an industrial product to validate its effectiveness. To this end, the formalization of an applicable methodology of Eco-UCD is the next step of this work. Besides, the long term objective of our work could be met by generating a concept of User Centered Design model with a particular attention to environmental interests, pushing obviously the research towards another level of consideration. That makes this "open window" an interesting prospect for future applications of Kansei studies.

\section{ACKNOWLEDGEMENTS}

The authors are grateful to the French National Research Agency for funding this project, and express their gratitude to all partners of the ECO-USE consortium for their collaboration.

\section{REFERENCES}

1. AFNOR (2002). ISO/TR 14062:2002. Environmental management -- Integrating environmental aspects into product design and development.

2. AFNOR (1998). ISO 9241-11:1998. Ergonomic requirements for office work with visual display terminals (VDTs) -- Part 11: Guidance on usability.

3. AFNOR (1999). ISO 13407:1999. Human-centred design processes for interactive systems.

4. Akrich, M. (1992). The description of technical objects, W.E. Bijker, J. Law, Editors. Shaping technology:

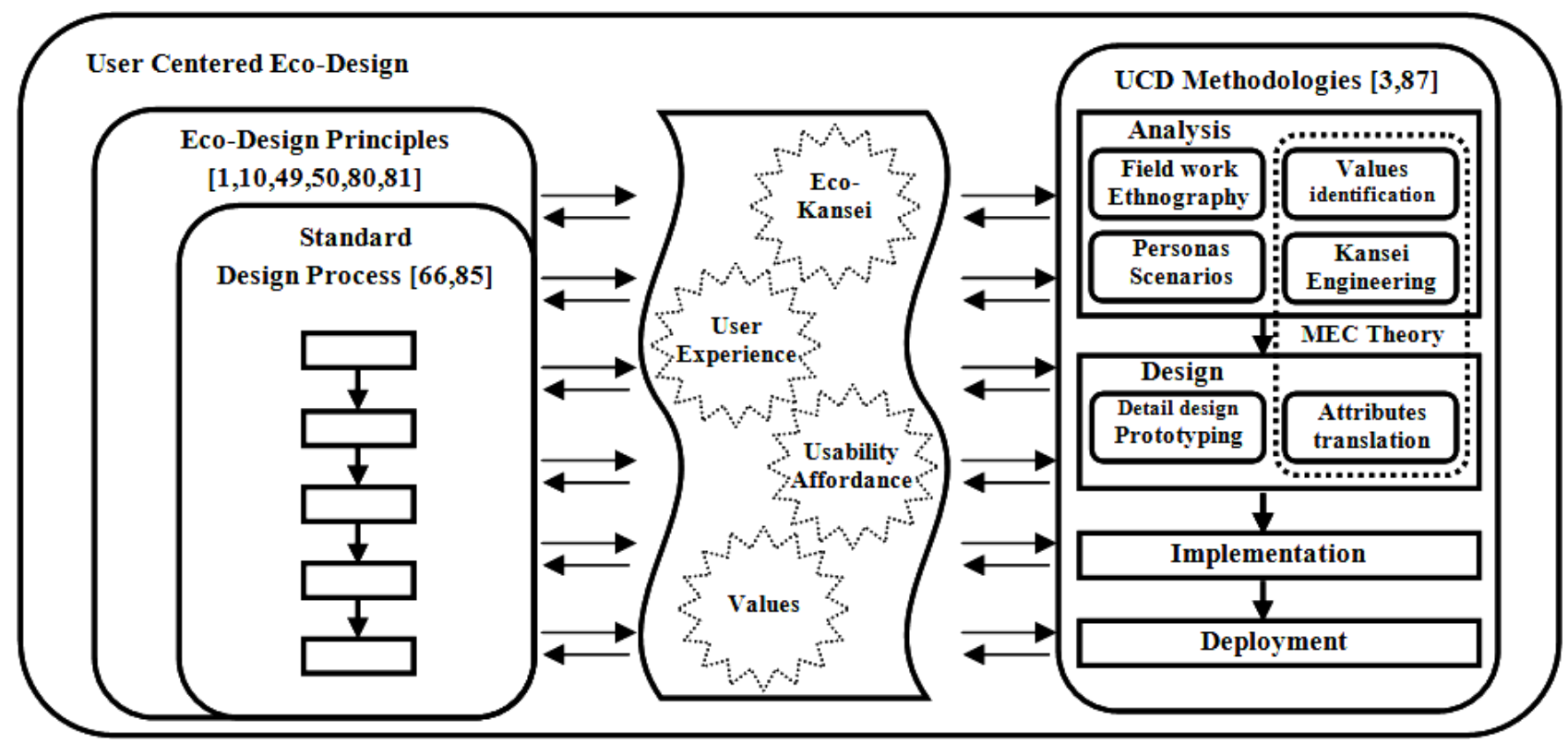

Figure 7: Proposed basic framework for a User-Centered Eco-design methodology. 
building society, Massachusetts Institute of Technology (MIT), Cambridge, MA (1992), pp.205-224.

5. Arroyo, E, Bonanni, L and Selker, T (2005). Waterbot: exploring feedback and persuasive techniques at the Sink, In: CHI 2005, Portland, OR, USA.

6. Baker, S. and Knox S. (1994). Product attributes and personal values: a review of means-end-theory and consumer behaviour, Cranfield Information \& Library Services.

7. Bhamra, T A, Lilley, D. and Tang, T. (2008). Sustainable use: changing consumer behaviour through product design. In Changing the change: design visions, proposals and tools, Turin, Italy, 10th-12th July 2008.

8. Blomkvist, S. (2002). Persona - an overview of Personae and goal-directed design, Retrieved November, 22, pp.1-8.

9. Blomkvist, S. (2002). The User as a Personality Using Personae as a Tool for Design, Position paper for the course workshop "Theoretical perspectives in Human-Computer Interaction" (HMI656) at IPLab, KTH.

10. Bonvoisin, J., Mathieux, F., Domingo, L. and Brissaud, D. (2010). Design for energy efficiency: proposition of a guidelines-based tool, In Proc. DESIGN 2010.

11. Bouchard, C. et al. (2009). A European emotional investigation in the field of shoe design, International Journal Of Product Development, 7(1), pp.3-27.

12. Bouchard, C., Brissaud, D. and Aoussat, A. (2010). User kansei Modelling and Ecodesign, Communication in GCMM2010.

13. Bouchard, C., Lim, D. and Aoussat, A. (2003). Development of a KANSEI ENGINEERING SYSTEM for Industrial design, Communication.

14. Brangier, E., and Bornet, C. (2011). Persona: A Method to Produce Representations Focused on Consumers' Needs, In Handbook of Human Factors and Ergonomics in Consumer Product Design. Edited by Waldemar Karwowski, Marcelo Soares, Neville A. Stanton. Published by CRC Press.

15. Carroll, JM (2000). Five reasons for scenario-based design. Interacting with Computers, Volume 13, Issue 1, September 2000, pp.43-60.

16. Chen CF., Yeh CH., Lin YC. (2009). A Kansei Engineering Approach to Eco-product Form Design, In Proc. of IASDR09.

17. Chu D. and Aoki H. (2009). Initiative of Service and Product Design Based on Kansei Engineering Construction of Design Methodology to Keep and
Improve Product Value, In Proc. of IASDR09.

18. Costa, A.I.A., Dekker, M., and Jongen, W.M.F. (2004). An overview of means-end theory : potential application in food product design, Trends in Food Science Technology, 15(7-8), pp.403-415.

19. Dahlgaard, J.J. and Schu, S. (2008). Kansei / affective engineering design, Group, 20(4), pp.299-311.

20. DEFRA (2008). A framework for pro-environmental behaviours. United Kingdom. Available at http://www. defra.gov.uk/publications/files/pb13574-behavioursreport-080110.pdf

21. Dekoninck, E. and Elias, E.W.A. (2011). Eco-Design: The Evolution of Dishwasher Design and the Potential for a More User-Centered Approach, In Handbook of Human Factors and Ergonomics in Consumer Product Design. Edited by Waldemar Karwowski, Marcelo Soares, Neville A. Stanton. CRC Press.

22. Desmet, P.M.A. and Hekkert, P. (2000). When a car makes you smile: development and application to measure product emotions, Advances in Consumer Research, Vol. 27, pp.11-117.

23. Dumas, JS. and Salzman, MC. (2006). Usability Assessment Methods. In Reviews of Human Factors and Ergonomics April 2006, Vol.2, No.1, pp.109-140.

24. Ecodesign Pilot. Available at http://www.ecodesign. at/pilot/online/english/index.htm

25. Eko-think.fr (2010). Eco-conception \& Eco-design : Le Développement Durable en pratique, acteurs, outils et solutions. Available at http://www.eko-think.fr/ conference/Eco-conception $\% 20 \mathrm{et} \% 20 \mathrm{e} \% \mathrm{CC} \% 81$ codesign \%20(Eko-think).pdf

26. Elias, E.W.A, Dekoninck, E.A. and Culley, S.J.C. (2008). Assessing user behaviour for changes in the design of energy using domestic products, In IEEE International Symposium on Electronics and the Environment (ISEE 2008), San Francisco, CA, US.

27. European Union (2005). Directive 2005/32/EC of the European Parliament and of the Council establishing a framework for the setting of ecodesign requirements for energy-using products and amending Council Directive 92/42/EEC and Directives 96/57/EC and 2000/55/EC of the European Parliament and of the Council, In Official Journal of the European Union. Available at http://eur-lex.europa.eu/LexUriServ/ LexUriServ.do?uri=OJ:L:2005:191:0029:0029:EN:PDF

28. European Union (2009). Directive 2009/125/EC of the European Parliament and of the Council of 21 October 2009 establishing a framework for the setting of ecodesign requirements for energy-related products (recast), In Official Journal of the European Union. 
Available at http://eur-lex.europa.eu/LexUriServ/ LexUriServ.do?uri=OJ:L:2005:191:0029:0029:EN:PDF

29. Fogg, BJ. (2003). Persuasive technology; using computers to change what we think and do, Morgan Kaufmann, San Francisco, USA.

30. Goodwin, K. (2002). Getting from research to personas: Harnessing the power of data.

Available at http://www.cooper.com/journal/2002/11/ getting_from_research_to_perso.html

31. Green, W.S. and Jordan, P.W. (2002). Pleasure with Products, Beyond Usability, Taylor and Francis, New York.

32. Grudin, J., and Pruitt, J. (2002). Personae, participatory design and product development: An infrastructure for engagement, In Proceedings of the participatory design conference (pp.144-161). ACM Press.

33. Han, S. (2000). Evaluation of product usability: development and validation of usability dimensions and design elements based on empirical models, International Journal of Industrial Ergonomics, 26(4), pp.477-488.

34. Hofstede, G. and Bond, M.H. (1984). Hofstede's culture dimensions, Journal of Cross-Cultural Psychology, 15(4), p.417.

35. Hofstede, G. (2009). Geert Hofstede Cultural Dimensions. Itim International, pp.3-5.

36. Hofstede, G., Hofstede, G.J. and Minkov, M. (2004). Cultures and Organizations, Cultures, p.1970-1970.

37. Holtzblatt, K. (2002). Personae and Contextual Design.

38. Jarvi, P. and Paloviita, A. (2007). Product-related information for sustainable use of laundry detergents in Finnish households, Journal of Cleaner Production, 15(7), pp.681-689.

39. Jelsma, J. and Knot, M. (2002). Designing environmentally efficient services; a 'script' approach, Journal of Sustainable Product Design, Vol.2, pp.119-130.

40. Jiao, J., Zhang, Y. and Helander, M. (2006). A Kansei mining system for affective design, Expert Systems with Applications, 30(4), pp.658-673.

41. Kim, J., and Moon, JY. (1998). Designing towards emotional usability in customer interfaces-trustworthiness of cyber-banking system interfaces, Interacting with Computers, 10(1), pp.1-29.

42. King, S.C. and Meiselman, H.L. (2010). Development of a method to measure consumer emotions associated with foods, Food Quality and Preference, 21(2), pp.168-177.

43. Kujala, S. and Kauppinen, M. (2004). Identifying and selecting users for user-centered design, Proceedings of the third Nordic conference on Human computer interaction NordiCHI 04, pp.297-303.

44. Levy, P. and Yamanaka, T. (2007). Interdisciplinary Design Method for EcoDesign: Introducing Kansei research for design to EcoDesign, Communication.

45. Lewis H., Gertsakis J., Grant, T., Morelli N. and Sweatman A. (2001). Design +environment, Greenleaf, Sheffield, UK.

46. Lilley, D. (2009). Design for sustainable behaviour: strategies and perceptions, Design Studies, Volume 30, Issue 6, November 2009, pp.704-720.

47. Lin, Y., Lai, H. and Yeh, C. (2007). Consumer-oriented product form design based on fuzzy logic: A case study of mobile phones, International Journal of Industrial Ergonomics, 37(6), pp.531-543.

48. Lockton, D. Harrison and N. Stanton (2008). Making the user more efficient: design for sustainable behaviour. International Journal of Sustainable Engineering, Vol.1, No.1, pp.3-8.

49. Lofthouse, V. (2006). Ecodesign tools for designers: defining the requirements, In Journal of Cleaner Production, 14(15-16), pp.1386-1395.

50. Lofthouse, V. A. and Lilley, D. (2006). What they really, really want: user centered research methods for design, International design conference - design 2006, Dubrovnik - Croatia, May 15-18, 2006.

51. Luttropp, C. and Lagerstedt, J. (2006). EcoDesign and The Ten Golden Rules: generic advice for merging environmental aspects into product development, Journal of Cleaner Production, 14(15-16), pp.1396-1408.

52. Maguire, M. (2001). Methods to support humancentred design, International Journal of Human-Computer Studies, Volume 55, Issue 4, October 2001, pp.587-634.

53. Mantelet, F. (2007). Prise en compte de la perception émotionnelle des consommateurs au sein du processus de conception de produits innovants, 7 e Congrès international de Génie Industriel - 5-8 Juin 2007 Trois-Rivières, Québec (Canada).

54. Mao, JY., Vrenderburg, K., Smith, PW., Carey, T. (2005). The state of user-centered design practice, In Communications of the ACM - The disappearing computer CACM, Volume 48, Issue 3.

55. McCalley, LT. and Midden, CJH. (2006). Making energy feedback work, P.P. Verbeek, A. Slob, Editors, User behavior and technology development: shaping sustainable relations between consumers and technologies, Springer, The Netherlands, pp.127-135.

56. Miaskiewicz, T. and Kozar, K.A. (2011). Personae and user-centered design: How can personae benefit product design processes? Design Studies, 32(5), 
pp.417-430.

57. Nagamachi, M. (1995). Kansei Engineering: A new ergonomic consumer-oriented technology for product development, International Journal of Industrial Ergonomics, Volume 15, Issue 1, January 1995, pp.3-11.

58. Navarro, O., Forest, F., Lavoisy, O., Chanal, V. (2009). L'utilisation du scénario dans le processus d'innovation: Une lecture pluridisciplinaire, Umanlab.com.

59. Nielsen, J. (1994). Usability inspection methods, J. Nielsen \& R. L. Mack, eds., ACM Press.

60. Norman, D.A. (1988). The Psychology of Everyday Things, Basic Books Inc. Publishers, NY.

61. Norman, D.A. (2004). Emotional Design, Basic Books, NY.

62. Noro K. and Imada AS. (1991). Participatory ergonomics, London, Eds. Taylor and Francis.

63. Olsen, G. (2004). Persona creation and usage toolkit. Available at http://www.interactionbydesign.com/ presentations/olsen_persona_toolkit.pdf

64. Osgood, C.E. (1969). The Nature and Measurement of the Meaning, Semantic Differential Technique, A Sourcebook. Aldline Publishing Company, Chicago.

65. Overbeeke, C.J. and Hekkert, P. (1999). First Conference on Design and Emotion, edited by dr. ISBN 90-9013288-0.

66. Pahl, G., Beitz, W., Feldhusen J. and Grote K.-H. (1994, ed. 2007). Engineering Design (3rd ed.), Springer, Berlin, Wallace K, Blessing L (Trans. and Eds.).

67. Petiot, J.F. and Yannou, B. (2004). Measuring perceptions for a better comprehension, specification and assessment of product semantics, International Journal of Industrial Ergonomics, Vol.33, January, pp.507-525.

68. Pruitt, J., and Grudin, J. (2003). Personas: Practice and theory, In Proceedings of the 2003 Conference on Designing for User Experience, pp.1-15, ACM.

69. Quarante, D. (1994). Eléments de design industriel, Polytechnica, Paris Maloine.

70. Reinecke, K., Minder, P. and Bernstein, A. (2011). MOCCA - A System That Learns and Recommends Visual Preferences Based on Cultural Similarity, In 2011 International Conference on Intelligent User Interfaces, pp.453-454.

71. Riaz, T. and Talib, K. (2010). User-Driven Innovation at local companies, Computer, (September), pp.1-72.

72. Rokeach, M. (1973). The Nature of Human Values, The Free Press, New York.

73. Roozenburg, N.F.M. and Eekels, J. (1995). Product Design: Fundamentals and Methods, John Wiley \& Sons.
74. Schifferstein, H. N. J., Mugge, R. and Hekkert P. (2004). Designing consumer-product attachment, In Design and Emotion: The Experience of Everyday Things, Taylor \& Francis.

75. Schütte, S. (2005). Engineering Emotional Values in Product Design -Kansei Engineering in Development, Engineering.

76. Schütte, S.T.W. et al. (2004). Concepts, methods and tools in Kansei engineering, Theoretical Issues in Ergonomics Science, 5(3), pp.214-231.

77. Shackel, B. (2009). Usability - Context, framework, definition, design and evaluation, Interacting with Computers, 21(5-6), pp.339-346.

78. Sherwin, C. (2004). Design and sustainability - A discussion paper based on personal experience and observation, The Journal of Sustainable Product Design. Vol.4. Springer Netherlands.

79. Steen, M., Kuijt-Evers, L. and Klok, J. (2007). Early user involvement in research and design projects $-A$ review of methods and practices, In Communication. Citeseer, pp.1-21.

80. Telenko, C. and Seepersad, C.C. (2010). A Methodology for Identifying Environmentally Conscious Guidelines for Product Design, In Journal of Mechanical Design, 132(9), p.091009.

81. Telenko, C., Seepersad, C.C. and Webber, M.E. (2008). A Compilation Of Design For Environment Principles And Guidelines, Engineering Conference.

82. Tischner, U., et al. (2000). How to do EcoDesign? A Guide for Environmentally and Economically Sound Design, Verlag Form Praxis, Germany, Frankfurt amMain.

83. TNS (2008). TNS Global Study "The Green Life" Reveals Spectrum of Environmental Attitudes Across United States and the World, Available at http://www. tnsglobal.com/_assets/files/TNS_Market_Research_ General_Green_4-30-08_Release.doc.pdf

84. Tsao, Y.-C. and Chan, S.-C. (2011). A study on embarrassment associated with product use, Applied Ergonomics, 42(3), pp.503-510.

85. Ulrich, K.T. and Eppinger, S.D. (2000, ed. 2007). Product Design and Development, MacGraw-Hill, New York.

86. Usability First. How well do you know your users? Available at www.usabilityfirst.com.

87. Usability Professionals' Association. What is UserCentered Design? Available at www.upassoc.org.

88. Ushada M. and Haruhiko M. (2009). Design of customisable greening material using swarm modelling, Biosystems Engineering, 104(2), pp.169-183. 
89. Valette Florence P. (1994). Introduction à l'analyse des chaînages cognitifs, Recherche et Application en marketing, Vol.9, No.1, pp.93-118.

90. Wever, R., Van Kuijk, J. and Boks, C. (2008). Usercentred design for sustainable behaviour, International Journal of Sustainable Engineering, Vol.1, No.1, pp.9-20.

91. Wimmer, W., and Züst, R. (2001). ECODESIGN Pilot: Product Investigation, Learning and Optimization Tool for Sustainable Product Development, Alliance for global sustainability bookseries (p.x, 99 p.). Kluwer Academic.

92. Wimmer, W., Züst, R. and Strasser, CH. (2002). The Application of the ECODESIGN PILOT and Methodical Support for the Implementation of ECODESIGN in Products, In Proc. Of 7th International Design Conference DESIGN 2002.

93. Yung, W.K.C. (2010). Green Design of Electronic Products, Ecodesign seminar, Hong Kong Polytechnic Univesity. Available at http://hkelectronicsfairse. hktdc.com/pdf/seminar_abridged_Prof_Yung.pdf

94. Zafarmand, S., Tauchi, T., Terauchi, F. and Kubo, M. (2009). An Analytical Study on Product Subjective Sustainability through Kansei Engineering Approach, Proc. in IASDR 2009.

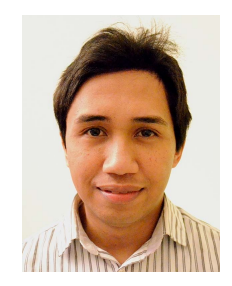

\section{Francis RASAMOELINA}

Francis Rasamoelina is a $\mathrm{PhD}$ candidate in the Product Design and Innovation Laboratory at Arts et Métiers, ParisTech, France. Francis is supervised by Professor Carole Bouchard, and focuses his work on the fields of Ecodesign, User-Centered Design and Kansei Design.

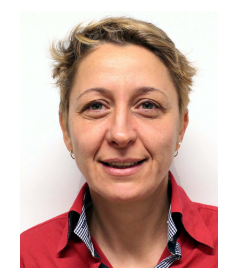

\section{Carole BOUCHARD}

Carole Bouchard is professor at Arts et Métiers, ParisTech, France. She teaches and guides research in the Product Design and Innovation Laboratory. She obtained her $\mathrm{PhD}$ in industrial engineering in 1997 in the field of automotive design and is professor since 2012. Her research focus lies on Kansei Design, as well as creativity and innovation in early design stages. She pilots various research projects that seek to develop innovative design tools to efficiently integrate the Kansei in the design process. Current projects are on user-centered Ecodesign methods, on word-based conception software for multidisciplinary teams, on the development of an immersive spatialized design workspace, etc. Carole was one of the organizers of KEER 2010.

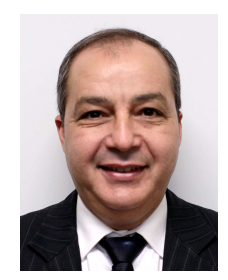

\section{Améziane AOUSSAT}

Améziane Aoussat is professor at Arts et Métiers, ParisTech, France and director of the Product Design and Innovation Laboratory since 1996. He obtained his $\mathrm{PhD}$ in 1990 and worked as research engineer. He practices as lecturer and researcher in the field of industrial engineering since 1995. His research focuses on the modeling of the product design process. Since 2000 he pilots research projects as a professor. He directs the work of his laboratory towards the Optimization of the Design and Innovation Process. Améziane is also editor-in-chief of the International Journal of Design and Innovation Research. 